\title{
Analyses of Factors Affecting the Browning of Model Processed Cheese during Storage
}

\author{
Kotomi ADACHI, Asuka Igoshi and Masatsune MuratA* \\ Department of Nutrition and Food Science, Ochanomizu University, 2-1-1 Otsuka, \\ Bunkyo-ku, Tokyo 112-8610 Japan \\ (Received December 27, 2019)
}

\begin{abstract}
Summary The purpose of this study was to clarify factors affecting the browning of a model processed cheese during storage. Model processed cheese samples ( $\mathrm{pH} 4.5-6.0)$ which were composed of sugars (galactose, glucose, or lactose; $0-1.8 \%$ ), amino acids (0-2.8\%), sodium caseinate (26.0-31.2\%), fat from butter (22.0-28.5\%), water (44.1\%), emulsifying salts (trisodium citrate, disodium tartrate dihydrate, or disodium hydrogen phosphate; 0 or $1.4 \%)$, and salt $(0-5.0 \%)$ were prepared. Each model processed cheese was stored at $50^{\circ} \mathrm{C}$ for $4-7 \mathrm{~d}$. The $L^{*-}, a^{*}$-, and $b^{*}$-values of model cheese samples before and after storage were measured and the $\Delta E$-value was calculated to estimate the browning. All model cheese samples turned brown during storage. The $\Delta E$-value strongly correlated with the concentration of galactose $(r=0.99)$, and $\mathrm{pH}(r=0.94)$, respectively. The galactose-added model cheese turned more intensively brown than glucose or lactose-added ones. The browning was not dependent on the amount of free amino acids, but on the amount of added sodium caseinate. The browning was repressed by the addition of 1 to $3 \%$ of NaCl. The model cheese added with disodium hydrogen phosphate as an emulsifying salt turned more intensively brown than those added with disodium tartrate dihydrate or trisodium citrate. The $\Delta E$-values of model cheese samples containing galactose strongly correlated with the decrease in galactose. These results showed that galactose was one of the most important factors for regulating the browning of processed cheese during storage and that the browning was also dependent on $\mathrm{pH}$, protein, $\mathrm{NaCl}$, and an emulsifying salt.
\end{abstract}

Key Words Maillard reaction, galactose, discoloration, emulsifier, non-enzymatic

Cheese is high in calories, and is also rich in protein, fat, vitamin, and calcium. Although cheese contains high amount of salt, it is usually distributed at low temperature to prevent putrefaction and keep its palatability. On the other hand, modern packaging and sterilization technology have made possible to distribute processed cheese and food products containing processed cheese at room temperature without losing its safety. However, we observed the browning of processed cheese during distribution and storage, which would reduce consumers' eagerness to buy. Although browning of cheese seems to be caused by the Maillard reaction, there is little chemically clear evidence on the relationship between the browning of cheese and the Maillard reaction. According to Standard Tables of Food Composition in Japan-2015 (7th revised version), processed cheese contains only $0.1 \%$ of available carbohydrates. Cheddar cheese is one of the major raw material for processed cheese. However, Igoshi et al. (1) recently compared several Cheddar cheese samples and identified D-galactose as a principal precursor of browning of a Cheddar cheese sample. Further, it was shown that sugar, especially D-galactose, was a limiting factor for

\footnotetext{
*To whom correspondence should be addressed.

E-mail: murata.masatsune@ocha.ac.jp
}

the Maillard reaction causing the browning of retail ripe or mature cheese during storage. On the other hand, the compositions of cheese are various, because of differences in raw materials, starter cultures, manufacturing methods, and storage periods. These factors may practically affect the browning of cheese. In fact, we have experienced that some cheese samples turned brown despite the low concentration of galactose. To regulate the browning of processed cheese and food products containing processed cheese during storage, we must know how each component or condition of the cheese to make an effect on the browning. To achieve this purpose, it is necessary to prepare model cheese samples having identified composition and to analyze it. In this present study, we prepared various model processed cheese samples and analyzed the browning during storage to clarify the relationship between the browning and the composition of processed cheese.

\section{MATERIALS AND METHODS}

Preparation of a standard model of processed cheese. A standard model processed cheese (Table 1) was prepared according to the methods of Tatsumi et al. (2) and Kwak et al. (3). Butter (Yukijirushi Hokkaido Butter (no salt), Megmilk Snow Brand, Sapporo, Japan) was molten at $80^{\circ} \mathrm{C}$, and the upper layer (butter fat) was collected. 
Table 1. Composition of the standard model processed cheese.

\begin{tabular}{lc}
\hline Materials & Ratio $(\%)$ \\
\hline Sodium caseinate & 26.0 \\
Free amino acids & 1.4 \\
Glu & 0.40 \\
Leu & 0.35 \\
Lys & 0.30 \\
Phe & 0.20 \\
Val & 0.15 \\
Water & 44.1 \\
Lactose & 1.3 \\
Butter fat & 27.2 \\
\hline
\end{tabular}

pH 5.0.

Sodium caseinate (6.50 g, FUJIFILM Wako Pure Chemical Corporation, Osaka, Japan), free amino acids (0.35 $\mathrm{g})$, whose composition was shown in Table 1 , butter fat $(6.80 \mathrm{~g})$, and water $(8.03 \mathrm{~g})$ were mixed in a metal cup, and then the mixture was homogenized on the boiling bath for 9 min with stirring. A galactose solution prepared from water $(3.00 \mathrm{~g})$ and D-galactose $(0.33 \mathrm{~g})$ was added to the homogenate, which was further stirred for 2 min.

Preparation of model cheese samples having various compositions. When each amount of a component was changed, its total amount was adjusted by the amount of added butter fat. Model cheese samples containing different amount of D-galactose from the standard model cheese were prepared as follows. Sodium caseinate $(6.50 \mathrm{~g})$, free amino acids $(0.35 \mathrm{~g})$, butter fat $(7.13$, $7.05,6.93,6.8$, and $6.68 \mathrm{~g}$ ), and water $(8.03 \mathrm{~g})$ were mixed. After each homogenate was prepared as described above, a galactose solution prepared from water $(3.00 \mathrm{~g})$ and D-galactose $(0,0.08,0.20,0.33$, and 0.45 g) was added to the homogenate, respectively.

Model cheese samples containing different kinds of sugars from the standard model cheese were prepared as follows. Sodium caseinate $(6.50 \mathrm{~g})$, free amino acids $(0.35 \mathrm{~g})$, butter fat $(6.96,6.96$, and $6.80 \mathrm{~g})$, and water $(8.03 \mathrm{~g})$ were mixed, and each homogenate was prepared as described above. Each sugar solution prepared from water $(3.00 \mathrm{~g})$ and D-galactose $(0.162 \mathrm{~g})$, D-glucose $(0.162 \mathrm{~g})$, and lactose $(0.325 \mathrm{~g})$ was added to the homogenate, respectively, as described above.

Model cheese samples with different $\mathrm{pH}$ from the standard model cheese were prepared as follows. Sodium caseinate $(6.50 \mathrm{~g})$, free amino acids $(0.35 \mathrm{~g})$, butter fat $(6.80 \mathrm{~g})$, and water $(8.03 \mathrm{~g})$ were mixed. The $\mathrm{pHs}$ of the samples were then adjusted to $4.5,5.0,5.5$, and 6.0 by adding $2 \mathrm{M} \mathrm{HCl}$ or $2 \mathrm{M} \mathrm{NaOH}$ to them. As described above, each homogenate was prepared, and a galactose solution having the standard composition was added to it.

Model cheese samples containing different amounts of sodium caseinate from the standard model cheese were prepared as follows. Sodium caseinate $(6.50,7.15$, and $7.80 \mathrm{~g})$, free amino acids $(0.35 \mathrm{~g})$, butter fat $(6.80$,
6.15 , and $5.50 \mathrm{~g})$, and water $(8.03 \mathrm{~g}$ ) were mixed, respectively. As described above, each homogenate was prepared, and a galactose solution having the standard composition was added to it.

Model cheese samples containing different amounts of free amino acids from the standard model cheese were prepared as follows. Sodium caseinate $(6.50 \mathrm{~g})$, free amino acids $(0,0.35,0.70$, and $1.05 \mathrm{~g})$, butter fat $(7.15,6.80,6.45$, and $6.10 \mathrm{~g})$, and water $(8.03 \mathrm{~g})$ was mixed, respectively. As described above, each homogenate was prepared, and a galactose solution having the standard composition was added to it.

Model cheese samples containing $\mathrm{NaCl}$ were prepared as follows. Sodium caseinate $(6.50 \mathrm{~g})$, free amino acids $(0.35 \mathrm{~g}), \mathrm{NaCl}(0,0.125,0.25,0.375,0.75$, and 1.25 g), butter fat $(6.80,6.675,6.55,6.425,6.05$, and $5.55 \mathrm{~g})$, and water $(8.03 \mathrm{~g}$ ) was mixed, respectively. As described above, each homogenate was prepared, and a galactose solution having the standard composition was added to it.

Model cheese samples containing various emulsifying salts were prepared as follows. Emulsifying agents were selected and added according to the literatures of Kapoor and Metzger (4) and El-Bakry et al. (5). Sodium caseinate $(6.5 \mathrm{~g})$, free amino acids $(0.35 \mathrm{~g})$, butter fat $(6.45 \mathrm{~g})$, emulsifying salt $(0.35 \mathrm{~g}$ of trisodium citrate, disodium tartrate dihydrate, or disodium hydrogen phosphate), and water (8.03 g) were mixed. Each sample was homogenized on the boiling bath for $6 \mathrm{~min}$, and a galactose solution having the standard composition was added to it.

Storage and measurements of the color difference of model processed cheese samples. Each model sample $(7 \mathrm{~g})$ was sealed in food grade plastic films (Hiryu N-4, Asahi Kasei Pax, Tokyo, Japan) using a heat sealer (SQ-303, Asahi Kasei Pax). They were stored at $50^{\circ} \mathrm{C}$ for 4 or $7 \mathrm{~d}$. The $L^{*}-, a^{*}$, and $b^{*}$-values of each sample were measured at five points with a color meter (NF333, Nippon Denshoku Industries, Tokyo). Samples were tested in triplicate. The $\Delta L^{*}-, \Delta a^{*}$-, and $\Delta b^{*}$-values of each sample between before and after storage were calculated. The $\Delta E$-values, the color difference, were calculated by the following equation:

$$
\Delta E=\left[\left(\Delta L^{*}\right)^{2}+\left(\Delta a^{*}\right)^{2}+\left(\Delta b^{*}\right)^{2}\right]^{1 / 2}
$$

Measurement of water activity. The water activity of the model cheese samples containing $\mathrm{NaCl}(0-5 \%)$ before storage was measured using a water activity meter (SP-W, AS ONE, Osaka, Japan).

Extraction and measurement of sugars. Sugars were determined by the internal standard method for HPLC analysis according to Mullin and Emmons (6) and Igoshi et al. (1) with some modifications. A model cheese sample was cut into small cubes. Fifty milliliters of $0.5 \mathrm{mg} /$ mL xylose (an internal standard) solution were added to $5 \mathrm{~g}$ of a model cheese sample, which was homogenized for $5 \mathrm{~min}$. The mixture was stirred at $50^{\circ} \mathrm{C}$ for $15 \mathrm{~min}$, before being cooled. Precipitate and two kinds of supernatant (upper and lower layers) were formed by centrifugation at $1,700 \times g$ for $5 \mathrm{~min}$ at $4^{\circ} \mathrm{C}$. Ethanol $(5 \mathrm{~mL})$ was added to an aliquot $(1 \mathrm{~mL})$ of the lower layer of the 
A

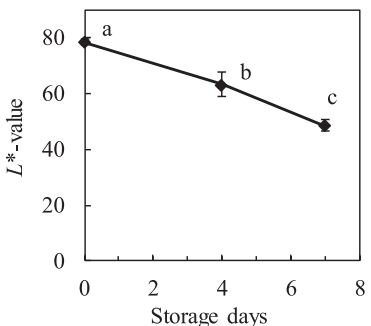

C

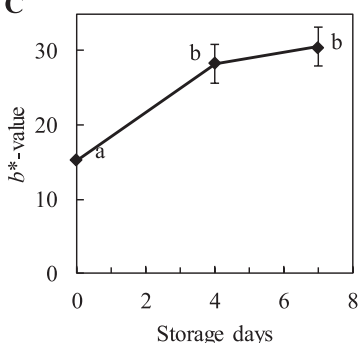

B
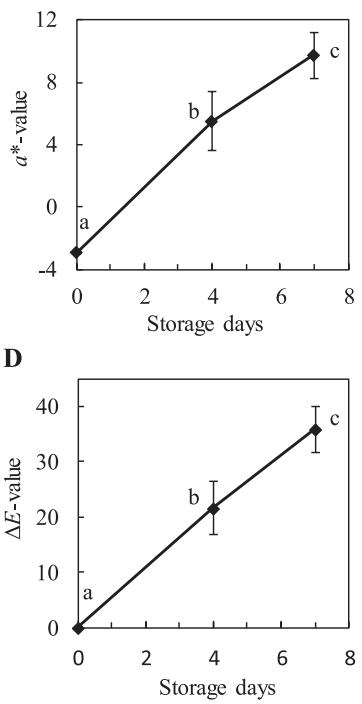

Fig. 1. Changes in $L^{*}-(\mathrm{A}), a^{*}-(\mathrm{B}), b^{*}-(\mathrm{C})$, and $\Delta E(\mathrm{D})$ values during storage of the standard model processed cheese sample at $50^{\circ} \mathrm{C}$. The composition and the preparation method were described in the "Materials and Methods" section. Different letters show a significant difference $(p<0.05 ; n=3)$.

supernatant, before being centrifuged at $1,700 \times g$ for $5 \mathrm{~min}$ at $4^{\circ} \mathrm{C}$. The supernatant was filtered and concentrated in vacuo. The obtained white powder was dissolved in $1.0 \mathrm{~mL}$ of water, to which $1.0 \mathrm{~mL}$ of acetonitrile was added. The solution was filtered and subjected to an HPLC device equipped with an evaporative lightscattering detector (ELSD).

HPLC. HPLC conditions were as follows: column, HILICpak VG-50 4E (i.d. $4.6 \mathrm{~mm} \times 250 \mathrm{~mm}$, Showa Denko, Tokyo) equipped with a guard column HILICpak VG-50G 4A (i.d. $4.6 \mathrm{~mm} \times 10 \mathrm{~mm}$, Showa Denko); eluent, acetonitrile : methanol : water $(85: 5: 10, \mathrm{v} / \mathrm{v} / \mathrm{v})$; flow rate, $1 \mathrm{~mL} / \mathrm{min}$; column temp., $60^{\circ} \mathrm{C}$; detector, Alltech 3300 ELSD (Alltech, Grace, IL). HPLC analyses were performed in duplicate for all samples. The retention times of D-galactose, D-glucose, and lactose were about 9,10 , and 18 min, respectively.

Statistical analysis. Statistical analyses were performed using Excel 2010 (Microsoft, Redmond, WA, USA) with the add-in software Statcel 4 (OMS, Tokorozawa, Japan). Differences among cheese samples were analyzed by one-way ANOVA, followed by the TukeyKramer multiple comparison test. The significance level was set at $p<0.05$.

\section{RESULTS AND DISCUSSION}

Effects of concentrations and kinds of sugar on the browning of model processed cheeses

The model standard processed cheese samples turned brown during storage for $7 \mathrm{~d}$. To promote the browning, we set storage temperature at $50^{\circ} \mathrm{C}$ here. As shown in Fig. 1 , the $L$-value of the model cheese decreased, while the $a^{*}-, b^{*}$, and $\Delta E$ values increased during storage with turning brown.
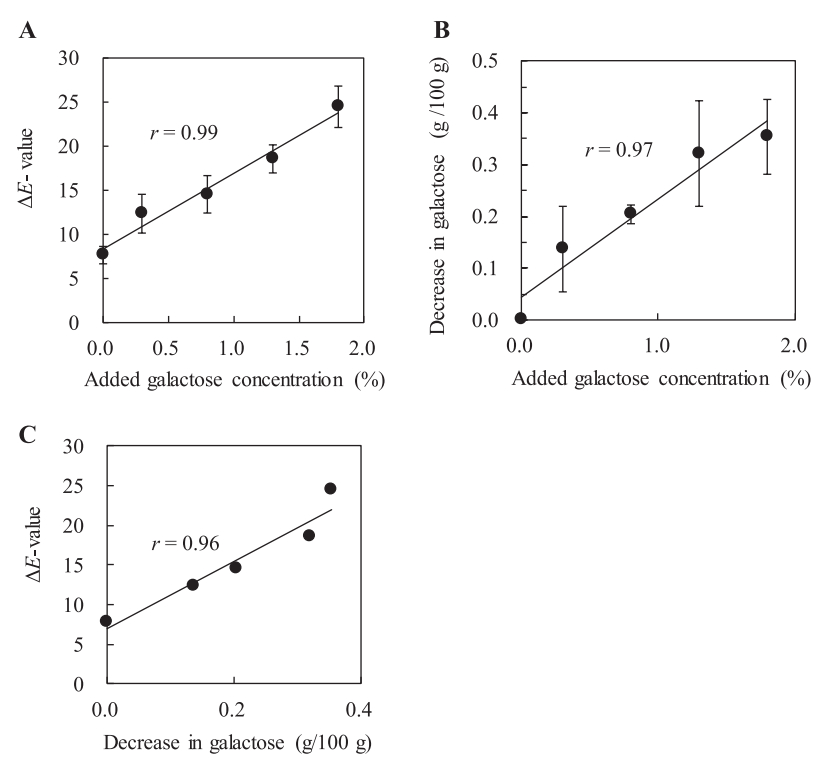

Fig. 2. Effect of added amounts of galactose on the $\Delta E$ value (A) and the amount of decrease in galactose (B) during storage, and a correlation between the decrease in galactose and the $\Delta E$-value (C). Each model cheese sample was stored at $50^{\circ} \mathrm{C}$ for $4 \mathrm{~d}(n=3)$.
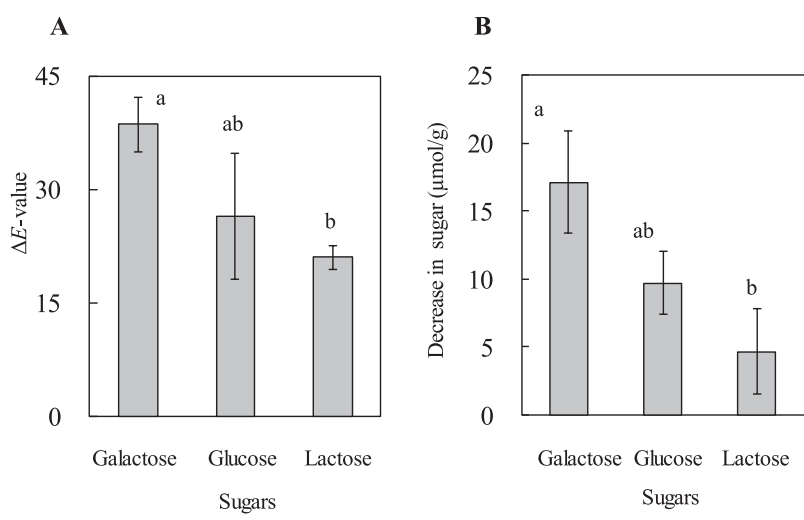

Fig. 3. Effects of added sugars (galactose, glucose, and lactose) on the $\Delta E$-value (A) and the amount of decrease in galactose (B) during storage. Each model cheese sample containing $0.65 \%$ glucose, $0.65 \%$ galactose or $1.3 \%$ lactose was stored at $50^{\circ} \mathrm{C}$ for $7 \mathrm{~d}$. Different letters show a significant difference $(p<0.05 ; n=3)$.

First, the dose effect of D-galactose on the browning of the model processed cheese was examined, because Igoshi et al. (1) suggested that D-galactose was the limiting factor for the browning of Cheddar cheese during storage. The browning or discoloration was evaluated using the $\Delta E$-value in this study. Figure $2 \mathrm{~A}$ shows the $\Delta E$-values of the model processed cheeses containing 0 , $0.3,0.8,1.3$, and $1.8 \%$ of D-galactose after $4 \mathrm{~d}$ storage at $50^{\circ} \mathrm{C}$. The $\Delta E$-values were apparently increased with the increase in the concentration of D-galactose $(r=$ 0.99). Next, we examined the decrease in D-galactose during storage, as we assumed that more galactose would be consumed with browning through the Maillard reaction. As a result, the more D-galactose was 
$\mathbf{A}$

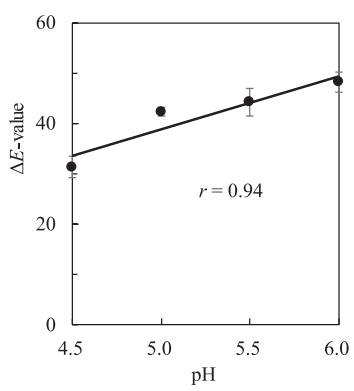

B

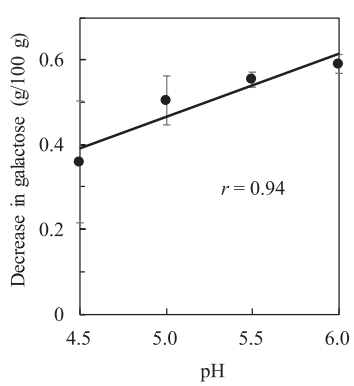

Fig. 4. Effects of $\mathrm{pH}$ on the $\Delta E$-value (A) and the amount of decrease in galactose (B) during storage. Each model cheese sample was stored at $50^{\circ} \mathrm{C}$ for $7 \mathrm{~d}$ $(n=3)$.

added, the more D-galactose was consumed during storage $(r=0.97$, Fig. 2B). The decrease in D-galactose also correlated with the $\Delta E$-value ( $r=0.96$, Fig. $2 \mathrm{C}$ ).

Next, the effects of kinds of sugar in the model cheese on the browning were examined. Figure $3 \mathrm{~A}$ shows the $\Delta E$-values of the model processed cheese samples containing $0.65 \%(36.1 \mu \mathrm{mol} / \mathrm{g})$ of D-galactose, $0.65 \%$ $(36.1 \mu \mathrm{mol} / \mathrm{g})$ of D-glucose, and $1.3 \%(38.0 \mu \mathrm{mol} / \mathrm{g})$ of lactose after $7 \mathrm{~d}$ storage at $50^{\circ} \mathrm{C}$. Among these model cheeses, the $\Delta E$-value of the galactose-added model cheese was 1.5 and 1.9 times higher than those of glucose- and lactose-added cheeses, respectively. As shown in Fig. 3B, D-galactose was most decreased. These results suggested that D-galactose most contributed to the browning among usual sugars in cheese.

Effects of $\mathrm{pH}$ on the browning of model processed cheese

The $\mathrm{pH}$ of the cheese is changeable by ripening environments such as varieties of lactic acid bacteria and periods of ripening. We can adjust $\mathrm{pH}$ of model processed cheese samples using $\mathrm{pH}$ adjusters. Then, the effects of pHs from 4.5 to 6.0 on the browning were examined. Figure $4 \mathrm{~A}$ and $4 \mathrm{~B}$ show the $\Delta E$-values and the decreases in D-galactose of the model processed cheese samples. The higher $\mathrm{pH}$ of the model cheese, the more intensive browning appeared. The $\mathrm{pH}$ correlated with the $\Delta E$-value $(r=0.94)$. The $\mathrm{pH}$ also correlated with the decrease in D-galactose $(r=0.94)$. These results indicated that the $\mathrm{pH}$ was a factor affecting the browning of cheese and that lower $\mathrm{pH}$ repressed the browning. In general, higher $\mathrm{pH}$ promoted the browning through the Maillard reaction (7).

Effects of sodium caseinate and free amino acids on the browning of model processed cheese

Amounts of proteins and free amino acids of cheese are also changeable by ripening environments such as varieties of lactic acid bacteria, periods of ripening, and used milk. Then, the dose effects of casein and free amino acids on the browning were examined. As the amount of added sodium caseinate was increased, the model cheese turned brown more intensively and promptly. Figure $5 \mathrm{~A}$ and $5 \mathrm{~B}$ show the $\Delta E$-values and the decreases in D-galactose of the model processed cheeses containing 26.0, 28.6, and $31.2 \%$ of sodium caseinate during storage. The $\Delta E$-value was increased
$\mathbf{A}$

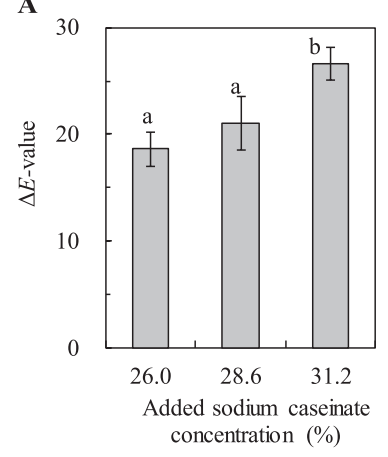

B

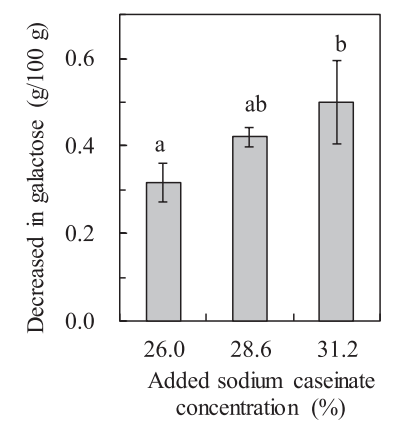

C

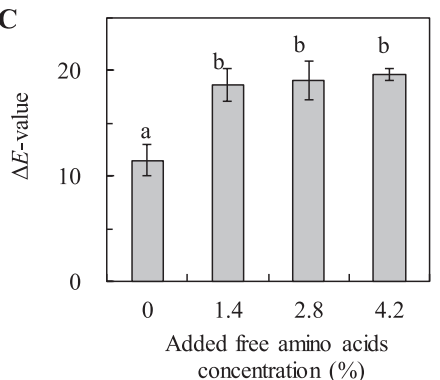

Fig. 5. Effect of added amounts of sodium caseinate (A and $\mathrm{B}$ ) and free amino acids (C) on the $\Delta E$-value (A and $\mathrm{C})$ and the amount of decrease in galactose (B) during storage. Each model cheese sample was stored at $50^{\circ} \mathrm{C}$ for $4 \mathrm{~d}$. Different letters show a significant difference $(p<0.05 ; n=3)$.

as the concentration of sodium caseinate was increased, and a significant difference was apparent between the model cheese samples containing $28.6 \%$ and $31.2 \%$ of sodium caseinate. Similarly, the decrease in D-galactose was increased as the concentration of sodium caseinate was increased.

When no free amino acids were added, the browning of the model cheese sample was significantly repressed (Fig. 5C). But no significant difference was apparent among the model cheese samples containing 1.4, 2.8, and $4.2 \%$ of free amino acids. These results suggested that the amount of sodium caseinate was a more important factor than those of amino acids on the browning in this model cheese system. Although we do not know the reason why caseinate contributed to the browning more intensively than free amino acids, there may be differences in the pigmentation or the process of the formation of brown pigments after the intermediate stage or the dicarbonyl formation between casein and amino acids. This might be related with that Hofmann described that the brown pigments in food formed through Maillard reaction are mainly derived from proteins but not from amino acids $(8)$.

Effects of $\mathrm{NaCl}$ on the browning of model processed cheese

Salt is usually added to cheese to prevent spoilage and to improve the taste. Then the dose effects of $\mathrm{NaCl}$ on the browning were examined. Figure $6 \mathrm{~A}$ and $6 \mathrm{~B}$ show the $\Delta E$-values and the decreases in D-galactose of the model processed cheeses containing $0,0.5,1.0,1.5,3.0$ and $5.0 \%$ of $\mathrm{NaCl}$ and stored at $50^{\circ} \mathrm{C}$ for $4 \mathrm{~d}$. The browning of the model cheese samples containing 1.0 to $3.0 \%$ of $\mathrm{NaCl}$ was repressed compared with the other samples, 
A
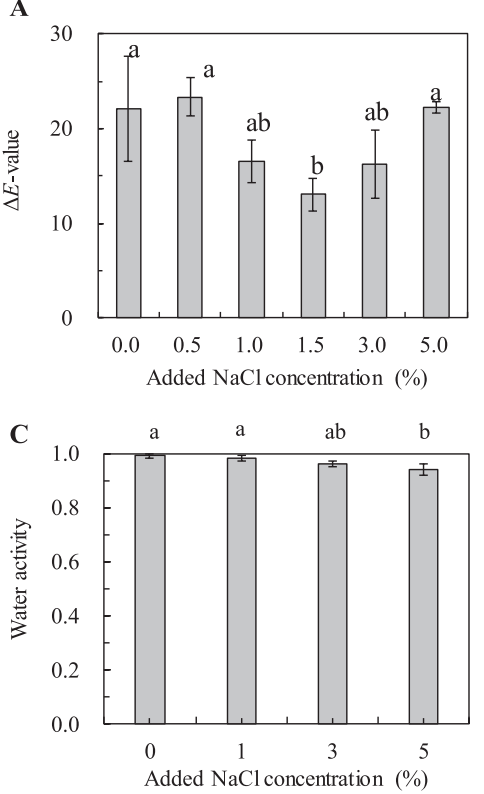

B

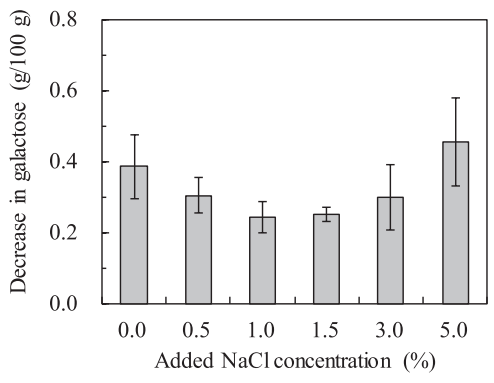

Fig. 6. Effect of added amounts of $\mathrm{NaCl}$ on the $\Delta E$-value (A) and the amount of decrease in galactose (B) during storage, and on the water activity of each model cheese before storage (C). Each model cheese sample was stored at $50^{\circ} \mathrm{C}$ for $4 \mathrm{~d}$. Different letters show a significant difference $(p<0.05 ; n=3)$.
A

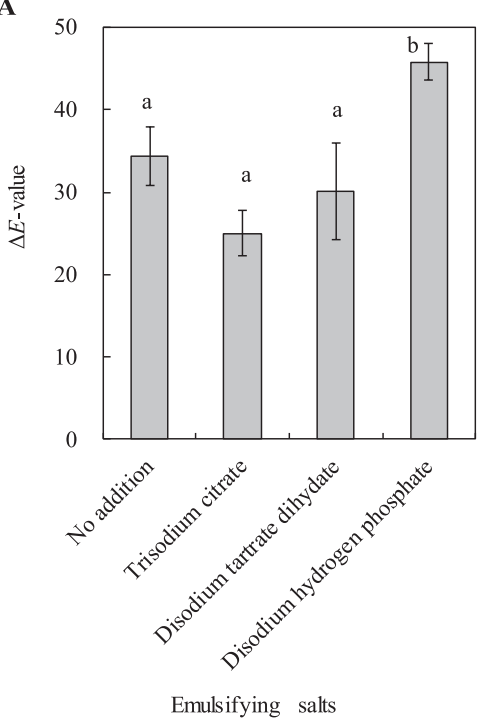

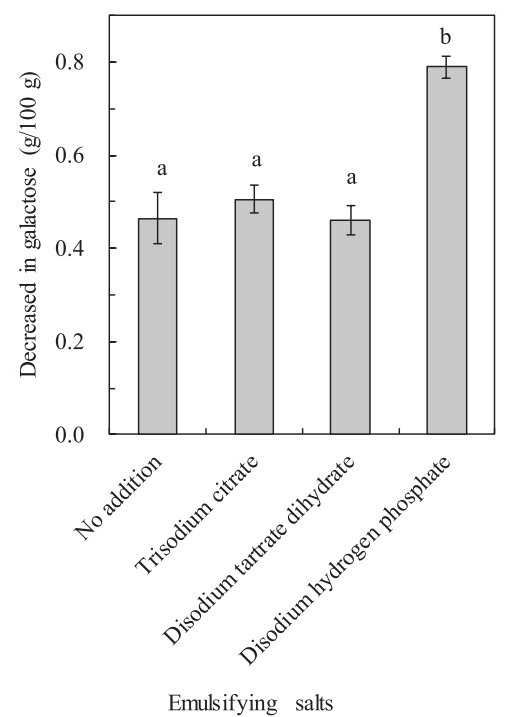

Fig. 7. Effects of added emulsifying salts (no addition (control), trisodium citrate, disodium tartrate dihydrate, and disodium hydrogen phosphate) on the $\Delta E$-value (A) and the amount of decrease in galactose (B) during storage. Each model cheese sample containing $1.4 \%$ emulsifying salt was stored at $50^{\circ} \mathrm{C}$ for $7 \mathrm{~d}$. Different letters show a significant difference $(p<0.05$; $n=3$ ). and the cheese containing $1.5 \%$ of $\mathrm{NaCl}$ showed the least browning. Although no significant differences in the decrease in D-galactose among model cheese samples were apparent, the decrease in D-galactose of the model cheese containing 1.0 to $3.0 \%$ of $\mathrm{NaCl}$ was less than those of the other samples. This result suggested that the addition of 1.0 to $3.0 \%$ of $\mathrm{NaCl}$ repressed the browning through the Maillard reaction of the model processed cheese. The water activity didn't seem to have a definite effect on the browning in this region of $\mathrm{NaCl}$ addition, although the water activity was decreased as the $\mathrm{NaCl}$ concentration was increased (Fig. 6C). This phenomenon might be explained by the fact that $\mathrm{NaCl}$ partly repressed the browning through the Maillard reaction (9) and that cations reduced the formation of a Schiff base (10). In general, the rate of the non-enzymatic browning increases with increasing water activity and then decreases at higher water activities as the browning reactants becoming diluted. The maximum rate is at the water activity of $0.5-0.8$, although there are a lot of variations $(11,12)$.

Effects of emulsifying salts on the browning of model processed cheeses

When processed cheese is manufactured, an emulsifying salt is generally added to provide a uniform structure during the melting process and improve the emulsifying capability of cheese proteins $(5,13)$. Then, the effects of three kinds of emulsifying salts (trisodium citrate, disodium tartrate dihydrate, and disodium hydrogen phosphate) on the browning were examined. When an emulsifying salt was added to the model cheese sample, the heating time for emulsifying was shortened by $3 \mathrm{~min}$ compared with the standard model cheese preparation, because the cheese added with an emulsifying salt was rapidly emulsified. Figure $7 \mathrm{~A}$ and $7 \mathrm{~B}$ show the $\Delta E$-values and the decreases in D-galactose of the model cheese samples containing $1.4 \%$ of trisodium citrate, disodium tartrate dihydrate, or disodium hydro- 


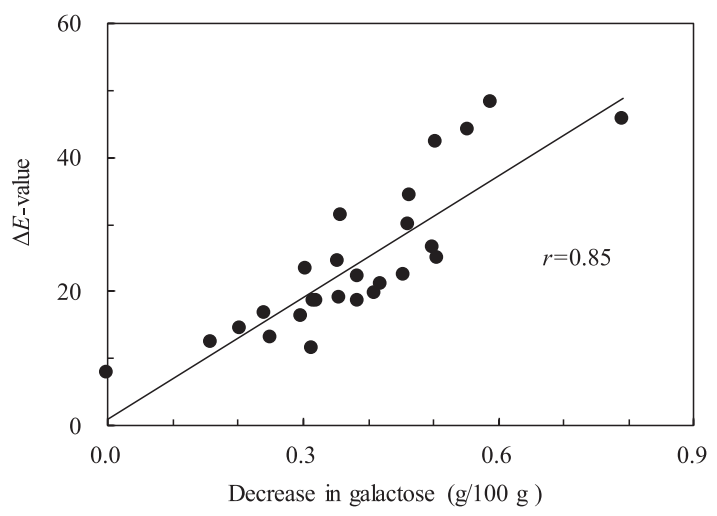

Fig. 8. Correlation between the $\Delta E$-values and the decreases in galactose of all model cheese samples containing galactose.

gen phosphate and stored at $50^{\circ} \mathrm{C}$ for $7 \mathrm{~d}$. The $\Delta E$-value and the decrease in D-galactose of the model cheese sample containing disodium hydrogen phosphate were, respectively, about 1.3 and 1.7 times larger than those of the standard model cheese. The addition of trisodium citrate or sodium tartrate showed no significant effect on the browning of the model cheese. This result was supported by the fact that phosphate ions promoted the Maillard reaction and browning $(7,14)$. The promotion of browning is associated with the enhancement of decomposition of sugars and Amadori compounds by phosphate or polyatomic anions (14). An emulsifying agent should be carefully selected from a standpoint of browning.

Figure 8 shows a correlation between the all the $\Delta E$ values and the decreases in D-galactose of model cheese samples containing D-galactose. The $\Delta E$-value correlated strongly with the decrease in D-galactose $(r=0.85)$. The result showed that D-galactose was a limiting factor for the browning of the model processed cheese.

This study also showed that D-galactose was the most important factor for the browning of the model processed cheese as well as Cheddar cheese (1). However, we should point out that the increase in $\mathrm{pH}$ and casein concentration, and the use of disodium hydrogen phosphate as an emulsifying agent promoted the browning of the model processed cheese. The browning of the model processed cheese was also affected by the concentration of $\mathrm{NaCl}$. The information clearly showed that we should pay attention to galactose concentration in natural cheese as raw materials at first and further to such other factors as $\mathrm{pH}$, concentrations of casein and $\mathrm{NaCl}$, and an emulsifying agent to develop a processed cheese hardly turning brown.

\section{Authorship}

Research conception and design: AI and MM; experiments: KA; interpretation of the data: KA, AI and MM; writing of the manuscript: $\mathrm{AI}$ and MM; supervision of the research: MM.
Disclosure of state of COI

No conflicts of interest to be declared.

\section{Acknowledgments}

This study was financially supported by a Grant-in-Aid for Scientific Research (B) [grant number 17H01958] from the Japan Society for the Promotion of Science.

\section{REFERENCES}

1) Igoshi A, Sato Y, Kameyama K, Murata M. 2017. Galactose is the limiting factor for the browning or discoloration of cheese during storage. J Nutr Sci Vitaminol 63: 412-418.

2) Tatsumi K, Nishiya T, Ido K, Kawanishi G. 1991. Effects of heat treatment on the meltability of processed cheese. Nippon Shokuhin Kogyo Gakkaishi 38: 102-106 (in Japanese).

3) Kwak HS, Jung CS, Shinm SY, Ahn J. 2002. Removal of cholesterol from cheddar cheese by $\beta$-cyclodextrin. J Agric Food Chem 50: 7293-7298.

4) Kapoor R, Metzger LE. 2008. Process cheese: Scientific and technological aspects-a review. Compr Rev Food Sci Food Saf 7: 194-214.

5) El-Bakry M, Duggan E, O'Riordan ED, O'Sullivan M. 2010. Effects of emulsifying salts reduction on imitation cheese manufacture and functional properties. J Food Eng 100: 596-603.

6) Mullin WJ, Emmons DB. 1997. Determination of organic acids and sugars in cheese, milk and whey by high performance liquid chromatography. Food Res Int 30: 147151.

7) Mikami Y, Murata M. 2015. Effects of sugar and buffer types, and $\mathrm{pH}$ on formation of Maillard pigments in the lysine model system. Food Sci Technol Res 21: 813-819.

8) Hofmann T. 1998. Studies on the relationship between molecular weight and the color potency of fractions obtained by thermal treatment of glucose/amino acid and glucose/protein solutions by using ultracentrifugation and color dilution techniques. J Agric Food Chem 46: 3891-3895.

9) Kwak EJ, Lim SI. 2004. The effect of sugar, amino acid, metal ion, and $\mathrm{NaCl}$ on the model Maillard reaction under pH control. Amino Acids 27: 85-90.

10) Gökmen V, Senyuva HZ. 2007. Effects of some cations on the formation of acrylamide and furfurals in glucoseasparagine model system. Food Res Technol 225: 815820.

11) Labuza TP, McNally L, Gallagher D, Hawkes J, Hurtado F. 1972. Stability of intermediate moisture foods. 1. Lipid oxidation. J Food Sci 37: 154-159.

12) Rajchasom S, Bronlund JE, Paterson AHJ, Bailey DG. 2012. The study of the effect of water activity on the browning kinetics of pastry at high process temperatures. Chemeca 2012: Quality of Life through Chemical Engineering, 23-26 September 2012, Wellington, New Zealand. p 406-413. Engineers Australia.

13) Awad RA, Abdel-Hamid B, El-Shabrawy SA, Singh RK. 2002. Texture and microstructure of block type processed cheese with formulated emulsifying salt mixtures. LWT Food Sci Technol 35: 54-61.

14) Rizzi G. 2004. Role of phosphate and carboxylate ions in Maillard browning. J Agric Food Chem 52: 953-957. 